\title{
Association of INPP1, PIK3CG, and TSC2 gene variants with autistic disorder: implications for phosphatidylinositol signalling in autism
}

\author{
F J Serajee, R Nabi, H Zhong, A H M Mahbubul Huq
}

J Med Genet 2003;40:1 19 (http://www.jmedgenet.com/cgi/content/full/40/11/119)

$E^{2}$ pidemiological studies have shown that about $43-86 \%$ of individuals with tuberous sclerosis complex have a pervasive developmental disorder similar to autism. Mutations in tuberous sclerosis genes TSCl and TSC2 disrupt the phosphatidylinositol signalling pathway downstream of the insulin / insulin-like growth factor receptor in the control of cell growth. ${ }^{2-5}$ We investigated single nucleotide polymorphisms in three phosphatidylinositol signalling genes that map to consensus areas of linkage to autism, using 196 trios from the Autism Genetics Resource Exchange. Polymorphisms in inositol polyphosphate-1-phosphatase (INPP1) at the 2q32, $\gamma$ catalytic subunit of phosphatidyl 3$\mathrm{OH}-$ kinase gene (PIK3CG) at $7 \mathrm{q} 22$, and TSC2 gene at 16p13.3, were investigated for association with autistic disorder. Transmission disequilibrium tests and haplotype analyses demonstrated a nominally positive association of polymorphisms in INPP1, PIK3CG, and TSC2 genes with autism, suggesting that phosphatidylinositol signalling may have a role in susceptibility to autism.

Autism spectrum disorders [MIM 209850], which include autism, Asperger's syndrome, and pervasive developmental disorder not otherwise specified, are characterised by impairments in communications and social interactions and the presence of stereotyped behaviours. Family, twin, and linkage data suggest that inheritance of autism is complex. ${ }^{6-8}$ Latent class analysis of twin and family data suggests that between two to 10 loci may act epistatically, ${ }^{6}$ although more than 15 loci have been suggested. ${ }^{9}$ Recent genome screening studies found that many regions distributed over many chromosomes had a multipoint maximum lod score greater than one. ${ }^{9-14}$ Several studies found evidence of linkage in overlapping regions, which are likely to represent true linkage findings. The most consistent results are for regions on chromosome $7 \mathrm{q}, 2 \mathrm{q}$ and $16 \mathrm{p} 13.3^{1{ }^{115-17}}$ The $16 \mathrm{pl} 3.3$ region harbours the locus for TSC2 gene. ${ }^{18}$

Autism occurs in a number of genetic conditions, such as fragile $X_{,}^{19}{ }^{20}$ phenylketonuria, ${ }^{21}$ tuberous sclerosis complex, ${ }^{22}$ Rett syndrome, ${ }^{23}$ and chromosomal anomalies, but the majority of cases of autism are of unknown aetiology. ${ }^{8}$ The risk of autism in patients with tuberous sclerosis complex (TSC) is higher than in any other known condition. Epidemiological studies have shown that about $50-60 \%$ of individuals with TSC have mental retardation and $43-86 \%$ a pervasive developmental disorder similar to autism. Similarly, epidemiological studies of children with autism have reported that TSC occurs on average in $1 \%$ of cases. ${ }^{1}$ The possible mechanisms mediating association between tuberous sclerosis and autism include linkage disequilibrium of closely linked loci and disruption of a common neural or developmental pathway. ${ }^{22}$

The protein products of the TSC genes, hamartin and tuberin, appear to act as tumour suppressors. Genetic analyses in mice and Drosophila indicate that TSCl and

\section{Key points}

- The risk of autism in patients with tuberous sclerosis complex is higher than in any other known condition.

- Mutations in tuberous sclerosis genes TSC1 and TSC2 disrupt the phosphatidylinositol signalling pathway downstream of insulin and insulin-like growth factor receptor in the control of cell growth.

- We investigated polymorphisms in three phosphatidylinositol signalling genes that map to consensus areas of linkage to autism for association with autism. The genes include inositol polyphosphate-1-phosphatase (INPP1) gene at 2q32, gamma catalytic subunit of phosphatidyl 3-OH-kinase (PIK3CG) gene at 7q22, and TSC2 gene at 16p13.3

- Transmission disequilibrium tests and haplotype analyses demonstrate that polymorphisms in INPPI, PIK3CG, and TSC2 genes are in linkage disequilibrium with autism, suggesting that phosphatidylinositol signalling may have a role in susceptibility to autism.

TSC2 function in the phosphatidylinositol signalling pathway downstream of the insulin / insulin-like growth factor receptor in the control of cell growth..$^{2-5} 2425$ The modulation of the activity of inositol signalling molecules is carried out by several kinases and phosphatases. ${ }^{26}$ Examples of such modulators include the phosphatidylinositol-3-OH kinases (PI3K), PTEN (phosphatases with tensin domain), and inositol polyphosphate 1-phosphatase (INPP1).

A review of the human genome maps reveals that PIK3CG, the gamma catalytic subunit of PI3K, maps to $7 \mathrm{q} 22$ in a consensus area of linkage to autism..$^{27}$ Similarly, the inositol polyphosphate-1-phosphatase (INPP1) gene, which codes for one of the enzymes involved in phosphatidylinositol signalling pathways, maps to $2 \mathrm{q} 32$, another consensus area of linkage to autism. ${ }^{11}{ }^{15-17} 29$ The PIK3CG, INPP1, and TSC2 genes are relatively small genes spanning 43,30 , and $41 \mathrm{~kb}$ of genomic DNA, respectively, with 12,6 , and 41 exons, respectively (National Center for Biotechnology Information Locus ID: 5294, 3268 and 7249). In this study, we investigated single nucleotide polymorphisms in the TSC2, INPP1, and PIK3CG genes for association with autism.

Abbreviations: TSC, tuberous sclerosis complex; AGRE, Autism Genetic Resource Exchange; TDT, transmission disequilibrium test; PDT, pedigree disequilibrium test 


\section{METHODS Subjects}

DNA samples from 196 families were obtained from the Autism Genetic Resource Exchange (AGRE). AGRE, developed and maintained by the Cure Autism Now Foundation, is a central repository of family DNA samples for genetic studies of autism. ${ }^{30}$ All AGRE families include at least two affected members with a diagnosis of autism, Asperger's syndrome, or pervasive developmental disorder not otherwise specified. Diagnoses of AGRE families are confirmed using the Autism Diagnostic Interview-Revised protocol (ADI-R). Details of medical histories, neurological examinations, Peabody scores, and Vineland scores are available at the AGRE web site (www.agre.org). ADI-R, ADOS, Raven, and Handedness testing results with all interview data points and computer scored algorithm results are also available. A small percentage of cases in an AGRE sample represents probands with possible secondary autism resulting from perinatal trauma, or an identified genetic syndrome such as Fragile X; however, these cases were not included in this study. For the present report, data from a total of 581 individuals (196 children) were available for analysis. Among the 196 affected individuals, the male/female ratio was 3.36 (151 boys and 45 girls), consistent with the increased prevalence of the disorder in boys. The mean age of the children at the time of testing was 7 years.

\section{Genotyping}

For this study we genotyped 196 trios, randomly selecting one affected sib from each multiplex family. Genotyping was done by a high throughput single base primer extension assay with oligonucleotide microarrays and fluorescence detection through Orchid BioSciences' SNP stream UHT services (www.orchidbio.com). Single base primer extension involves the annealing of an oligonucleotide primer to a single-stranded PCR amplicon at a location which lies immediately adjacent to, but not including, the polymorphic SNP site. This is followed by enzymatic extension of the primer in the presence only of chain terminating dideoxynucleotides, which are labelled to facilitate subsequent detection of the identity of the single incorporated nucleotide.

\section{Statistical and genetic analysis}

The programs PedCheck and Merlin were used to detect genotyping errors. ${ }^{31}{ }^{32}$ Mistyping analyses were also performed using Sim Walk2. ${ }^{33}$ Marker allele frequencies were obtained by counting parental genotypes. Linkage disequilibrium between the markers was analysed by the Sim Walk2 and GOLD software packages using parental gametic haplotypes. ${ }^{33}{ }^{34}$ The standardised pairwise disequilibrium value $\mathrm{D}^{\prime}$ and the coefficient of disequilibrium $\mathrm{D}$ were calculated. $\mathrm{D}$ is the difference between the observed haplotype frequency and the frequency expected under statistical independence. The $\mathrm{D}^{\prime}$ measure is a proportion of the maximum value of $\mathrm{D}$, whose range extends from -1 to +1 , with -1 and +1 representing complete $\mathrm{LD}$ and 0 representing free association.

Family based association analyses were carried out using the transmission disequilibrium test (TDT), in which preferential allelic transmission from heterozygous parents to affected offspring is tested by applying the $(b-c)^{2} /(b+c)$ statistics and the $\chi^{2}$ test. $^{35}$ The transmission ratio (transmitted / not transmitted) and the 95\% confidence interval around the transmission ratio were calculated for each allele of the SNPs. Under a multiplicative model the transmission ratio is an estimator of the genotype relative risk. ${ }^{36}$ Transmission disequilibrium was calculated for pairwise haplotypes for adjacent markers using the TDT2 implementation in GENEHUNTER 2.1. ${ }^{37}$ Haplotypes of the SNPs in the INPP1 and TSC2 genes were constructed using a maximum likelihood method on the basis of transmission patterns in families in which both the parents were genotyped. For each haplotype, a test with $1 \mathrm{df}$ for excess transmission of that haplotype was calculated. Finally, a global test was also performed with $\mathrm{H}-\mathrm{l} \mathrm{df}$, by summing the $\chi^{2}$ values for each haplotype and multiplying the sum by $(\mathrm{H}-\mathrm{l})$ / $\mathrm{H}$, where $\mathrm{H}$ is the number of haplotypes for which transmission data are available. This statistic is approximately $\chi^{2}$ with $\mathrm{H}-1$ degrees of freedom. ${ }^{35} 39$

\section{RESULTS}

For the present study, a total of 196 trios (581 individuals) were available. For seven families only one parent was available. Only one randomly selected affected sib from each multiplex family was genotyped. In this situation, TDT is a valid test for association. ${ }^{35}$

\section{INPP 1 gene SNPs}

We genotyped a G/T SNP in exon 2 at the amino acid position 51 (dbSNP rs4656: T51T) and an A/G SNP in exon 3 at the amino acid position 116 (dbSNP rs4940: V116V) in INPPl gene. Genotyping success rates were $83.65 \%$ and $96.39 \%$, respectively. All results were consistent with Mendelian transmission. The markers were in Hardy-Weinberg equilibrium. The G/T and A/G SNPs were 6522 bp apart but in strong linkage disequilibrium $\left(\mathrm{D}^{\prime}=0.784\right)$. The allele and genotype frequencies are shown in table 1.

TDT studies revealed that these two SNPs in INPPl gene were nominally associated with autism (dbSNP rs4656, p = 0.02 ; and dbSNP rs4940, p $=0.02$ ) (table 2). The pedigree disequilibrium test (PDT) provides another general test of linkage disequilibrium. ${ }^{40}{ }^{41}$ We analysed the INPPl genotype data with PDT, which demonstrated nominally positive association of autism with the rs4656: G/T (SUM PDT: $\chi^{2}=$ 5.252, $\mathrm{df}=1, \mathrm{p}=0.0219$; AVE PDT: $\chi^{2}=5.252, \mathrm{df}=1$, $\mathrm{p}=0.0219)$ and rs4940 A/G (SUM PDT: $\chi^{2}=5.762, \mathrm{df}=1$, $\mathrm{p}=0.0164 ;$ AVE PDT: $\chi^{2}=5.762, \mathrm{df}=1, \mathrm{p}=0.0164$ ) polymorphisms. To detect linkage disequilibrium between the INPPI haplotypes and autism, we reconstructed haplotypes transmitted to autistic subjects. The number of haplotypes was less than the number of genotypes because of an ambiguous phase in some cases. There was a significant difference in the transmission of haplotypes to subjects with autistic disorder (global $\chi^{2}=11.6, \mathrm{df}=2, \mathrm{p}=0.003$ ). The GG haplotype was more often transmitted ( $p=0.0027)$ and the AT haplotype was less often transmitted $(p=0.0045)$.

Only one randomly selected affected sib from each multiplex family was genotyped. Under a multiplicative model the transmission ratio is an estimator of the genotype relative risk. Haplotypes were created by the maximum likelihood method. The number of haplotypes was less than the number of genotypes due to the ambiguous phase in some cases.

\section{PIK3CG gene SNPs}

PIK3CG maps to 7q22, a consensus area of linkage for autism. We genotyped a C/T SNP in exon 4 at the mRNA position 2335 (dbSNP rsl129293: NM_002649.2: S2335S) in the PIK3CG gene in 196 parent child trios. The PIK3CG polymorphism is located in the accessory domain (PIK domain), ${ }^{42}$ but does not change the amino acid composition (S2335S). The PIK domain is conserved in all PI3 and PI4 kinases, and may have a role in substrate presentation. ${ }^{42}$ The genotyping success rate by single base primer extension was $88.98 \%$. Of 517 genotypes, one genotype had Mendelian error $(<0.02 \%)$. The marker was in Hardy-Weinberg equilibrium. The allele and genotype frequencies are shown in table 1. TDT studies demonstrated that the polymorphism in the PIK3CG was in linkage disequilibrium with autism in 196 trios $(\mathrm{p}=0.04)$ (table 2$)$. 
Table 1 Allele and genotype frequency in 196 Autistic Genetic Resource Exchange multiplex families

\begin{tabular}{|c|c|c|c|c|c|c|c|c|}
\hline \multirow[b]{2}{*}{ Gene } & \multirow[b]{2}{*}{ dbSNP ID } & \multirow[b]{2}{*}{ Location } & \multirow[b]{2}{*}{ Allele } & \multicolumn{2}{|c|}{ Frequency } & \multirow[b]{2}{*}{ Genotype } & \multicolumn{2}{|c|}{ Frequency } \\
\hline & & & & Parents & Autistic & & Parents & Autistic \\
\hline \multirow[t]{3}{*}{ INPPI } & rs 4656 & Exon 2 & G & 0.7056 & 0.7576 & GG & 0.4984 & 0.5636 \\
\hline & & & T & 0.2944 & 0.2424 & GT & 0.4143 & 0.3879 \\
\hline & & & & & & $\pi$ & 0.0872 & 0.0485 \\
\hline \multirow[t]{3}{*}{ |NPPI } & rs 4940 & Exon 3 & A & 0.2344 & 0.2042 & AA & 0.065 & 0.0419 \\
\hline & & & G & 0.7656 & 0.7958 & AG & 0.3388 & 0.3246 \\
\hline & & & & & & GG & 0.5962 & 0.6335 \\
\hline \multirow[t]{3}{*}{ PIKЗCG } & rsl1129293 & Exon 4 & C & 0.7214 & 0.7543 & $\mathrm{CC}$ & 0.5249 & 0.5665 \\
\hline & & & T & 0.2786 & 0.2457 & CT & 0.393 & 0.3757 \\
\hline & & & & & & $\pi$ & 0.0821 & 0.0578 \\
\hline \multirow[t]{3}{*}{ TSC2 } & rs2073636 & Intron 4 & C & 0.6194 & 0.6534 & CC & 0.4179 & 0.4545 \\
\hline & & & $\mathrm{T}$ & 0.3806 & 0.3466 & CT & 0.403 & 0.3977 \\
\hline & & & & & & $\pi$ & 0.1791 & 0.1477 \\
\hline \multirow[t]{3}{*}{ TSC2 } & rs2074968 & Intron 9 & C & 0.5428 & 0.5621 & CC & 0.3127 & 0.3277 \\
\hline & & & G & 0.4572 & 0.4379 & CG & 0.4602 & 0.4689 \\
\hline & & & & & & GG & 0.2271 & 0.2034 \\
\hline \multirow[t]{3}{*}{ TSC2 } & rs7714 & Exon 40 & A & 0.825 & 0.848 & AA & 0.675 & 0.7059 \\
\hline & & & G & 0.175 & 0.152 & AG & 0.3 & 0.2843 \\
\hline & & & & & & GG & 0.025 & 0.0098 \\
\hline
\end{tabular}

Table 2 Transmission disequilibrium tests in 196 trios

\begin{tabular}{|c|c|c|c|c|c|c|c|c|}
\hline Gene & dbSNP ID & $\begin{array}{l}\text { Allele/ } \\
\text { haplotype }\end{array}$ & $\mathbf{T}$ & NT & $\chi^{2}$ & $p$ Value & $\begin{array}{l}\text { Ratio } \\
\text { (T/NT) }\end{array}$ & $\begin{array}{l}95 \% \mathrm{Cl} \\
\text { for ratio }\end{array}$ \\
\hline \multirow[t]{4}{*}{ INPP1 } & \multirow[t]{2}{*}{ rs 4656} & G & 56 & 34 & 5.38 & 0.020 & 1.65 & $1.09-2.60$ \\
\hline & & $\mathrm{T}$ & 34 & 56 & 5.38 & 0.020 & 0.61 & $0.38-0.92$ \\
\hline & \multirow[t]{2}{*}{ rs4940 } & A & 45 & 70 & 5.43 & 0.019 & 0.64 & $0.43-0.92$ \\
\hline & & G & 70 & 45 & 5.43 & 0.019 & 1.56 & $1.08-2.31$ \\
\hline \multirow[t]{2}{*}{ PIK3CG } & \multirow[t]{2}{*}{ rs11129293 } & C & 64 & 43 & 4.12 & 0.042 & 1.49 & $1.02-2.24$ \\
\hline & & $T$ & 43 & 64 & 4.12 & 0.042 & 0.67 & $0.45-0.98$ \\
\hline \multirow[t]{2}{*}{ TSC2 } & \multirow[t]{2}{*}{ rs2073636 } & C & 64 & 45 & 3.31 & 0.068 & 1.42 & $0.98-2.12$ \\
\hline & & $\mathrm{T}$ & 45 & 64 & 3.31 & 0.068 & 0.70 & $0.47-1.02$ \\
\hline \multirow[t]{2}{*}{ TSC2 } & \multirow[t]{2}{*}{ rs2074968 } & $C$ & 71 & 57 & 1.53 & 0.216 & 1.25 & $0.88-1.78$ \\
\hline & & G & 57 & 71 & 1.53 & 0.216 & 0.80 & $0.56-1.13$ \\
\hline \multicolumn{2}{|c|}{ INPPI haplotypes } & $A G+G T$ & 6 & 8 & 0.29 & 0.59 & 0.75 & $0.20-2.20$ \\
\hline \multicolumn{2}{|c|}{ Global $\chi^{2}=11.6, d f=2$} & AT & 19 & 41 & 8.07 & 0.0045 & 0.46 & $0.25-0.77$ \\
\hline \multicolumn{2}{|c|}{$p=0.003$} & GG & 44 & 20 & 9 & 0.0027 & 2.2 & $1.35-4.03$ \\
\hline \multicolumn{2}{|c|}{ TSC2 haplotypes } & $\mathrm{CC}$ & 46 & 29 & 3.85 & 0.050 & 1.64 & $1.04-2.73$ \\
\hline \multicolumn{2}{|c|}{ Global $\chi^{2}=4.73, \mathrm{df}=2$} & $\mathrm{CG}+\mathrm{TC}$ & 9 & 13 & 0.72 & 0.40 & 0.69 & $0.26-1.59$ \\
\hline \multicolumn{2}{|c|}{$p=0.09$} & TG & 27 & 40 & 2.52 & 0.112 & 0.68 & $0.40-1.09$ \\
\hline
\end{tabular}

\section{TSC2 gene SNPs}

Several studies provide evidence suggesting linkage of autism for regions on chromosome $16 \mathrm{p} 13.3$, the location of the TSC2 gene. ${ }^{115-17} \mathrm{~A}$ polymorphism in exon 40 at amino acid position 1734 (dbSNP rs7714: A/G) had a low genotyping success rate $(51.4 \%)$ and was not further analysed. A review of the literature and databases did not reveal any other exonic SNPs with suitable allele frequency. We genotyped a C/G SNP (dbSNP rs2074968) in intron 9, 100 bp $5^{\prime}$ to exon 10, a C/T SNP in intron 4 (dbSNP 2073636), and 348 bp $5^{\prime}$ to exon 5 in the TSC2 gene. Genotyping success rates were $91.39 \%$ and $87.8 \%$, respectively. Of 1051 genotypes, eight had Mendelian errors $(<1 \%)$. The markers were in Hardy-Weinberg equilibrium. The intron 4 and intron 9 SNPs were 5520 bp apart and in strong disequilibrium $\left(\mathrm{D}^{\prime}=0.818\right)$, whereas the exon 40 SNP was in a different haplotype block. D' between intron 4 and exon 40 SNP was 0.068, and $\mathrm{D}^{\prime}$ between intron 9 and exon 40 SNP was 0.092 . The allele and genotype frequencies are shown in table 1 .

TDT studies of the $\mathrm{C} / \mathrm{T}$ polymorphism in intron 4 of the TSC2 gene demonstrated nominal evidence for association (dbSNP rs2073636, intron $4 \mathrm{C} / \mathrm{T}, \mathrm{p}=0.056$ ) (table 2). TDT analyses revealed a difference in the transmission of haplotypes to subjects with autistic disorder (global $\chi^{2}=4.73, \mathrm{df}=2, \mathrm{p}=$ $0.09)$. The CC haplotype was more often transmitted $(p=0.050)$.

\section{Power analyses}

The program TDT Power Calculator (TDT-PC $v$ 1.2), based on Knapp's first approximation, was used to estimate power for the TDT analyses. ${ }^{43}$ We calculated the POWER of our studies with the different SNPs to detect a gene effect with genotypic relative risk $g=4.0$ for the homozygote and $g=$ 2.0 for the heterozygote, assuming a significance level of alpha $=5 \times 10^{-8}, 0.0001,0.001$, and 0.01 . The results are shown in table 3 . We had enough power to detect association at a significance level of alpha $=0.0001$.

Table 3 POWER calculation for the SNPs used in the study

\begin{tabular}{llllll}
\hline \multirow{7}{*}{ Gene } & dbSNP ID & $\mathbf{5 \times 1 0 ^ { - 8 }}$ & $\mathbf{0 . 0 0 0 1}$ & $\mathbf{0 . 0 0 1}$ & $\mathbf{0 . 0 1}$ \\
\cline { 3 - 6 } & & 0.21 & 0.81 & 0.93 & 0.99 \\
INPP1 & rs4656 & 0.15 & 0.73 & 0.89 & 0.98 \\
INPP1 & rs4940 & 0.15 & 0.92 & 0.98 \\
PIK3CG & rs1129293 & 0.20 & 0.78 & 0.92 & 0.99 \\
TSC2 & rs2073636 & 0.27 & 0.84 & 0.95 & 0.99 \\
TSC2 & rs2074968 & 0.27 & 0.85 & 0.95 & 0.95 \\
\hline
\end{tabular}




\section{DISCUSSION}

Our studies demonstrate that SNPs in three phosphatidylinositol signalling pathway genes, INPP1, PIK3CG, and TSC2, are in linkage disequilibrium with autism. TSC2 functions in the phosphatidylinositol-3-OH kinase (PI3K) pathway, downstream of the insulin / insulin-like growth factor receptor in the control of cell growth. The phosphatidylinositol 3-kinase pathway regulates TSC by phosphorylation of tuberin. ${ }^{5}$ The PIK3CG gene is a member of a family of genes coding for enzymes that phosphorylate the 3'-hydroxyl of phosphatidylinositol. INPPI enzyme removes the phosphate group at position 1 of the inositol ring from polyphosphates such as inositol 1,4-bisphosphate and inositol 1,3,4-trisphophosphate. These three genes map to consensus areas of linkage to autism.

Inositol and phosphatidylinositol phosphates are important for numerous cellular processes: neuronal survival; differentiation, neuroprotection, and transduction of signals from growth factors; neurotransmitters; and $G$ protein coupled receptors. ${ }^{45}{ }^{48}$ The associations of the three candidate genes with autism thus have neurobiological plausibility.

Although several consensus regions of linkage for autism have been identified on many different chromosomes, the task of identifying the responsible genes remains a formidable problem. Direct analysis of the likely candidate genes and single nucleotide polymorphism based linkage disequilibrium mapping are thus valid strategies for the identification of the autism susceptibility gene. For initial studies, the list of candidate genes can be narrowed according to insights obtained from secondary causes of autism such as TSC. As the risk of autism in patients with TSC is so high, it is likely that the developmental and signalling pathway that is abnormal in TSC plays in a role in the susceptibility to autism. Interestingly, a mutation of PTEN, which is a negative regulation of cell growth in the phosphatidylinositol signalling pathway, has been reported to cause autistic features. ${ }^{49}$

The exon polymorphisms in the INPPI and PIK3CG genes are not expected to change the amino acid composition of the respective proteins. These SNPs are not likely aetiological variants but may be in linkage disequilibrium with aetiological variants. This conclusion is supported by the observation that, in each case, the common allele of the SNPs is transmitted more often from heterozygous parents to the autistic subjects (tables 1 and 2).

The $\mathrm{p}$ values described here are nominal and were not corrected for multiple testing. POWER analyses suggested that we had sufficient power to detect association with a significance level of $0.000 \mathrm{l}$, but not a genome wide significance level (alpha $=5 \times 10-8)$ (table 3 ). However, the nominally positive $(\mathrm{p}<0.05)$ association of three positional candidate genes that all act in the phosphatidylinositol signalling pathway is still of interest and suggests that phosphatidylinositol signalling plays a role in susceptibility to autism.

\section{ACKNOWLEDGEMENTS}

We acknowledge support from Cure Autism Now and the Autism Genetic Resource Exchange (AGRE). We are grateful for the resources provided by the AGRE consortium and the participating AGRE families.

\section{Authors' affiliations \\ F J Serajee, R Nabi, H Zhong, A H M Mahbubul Huq, Department of Pediatrics}

A H M Mahbubul Huq, Department of Neurology, Wayne State University, Detroit, USA

The study described here was supported in part by a grant from the Children's Research Center of Michigan.
Correspondence to: $\operatorname{Dr}$ A H M Mahbubul Huq, Division of Neurology, Children's Hospital of Michigan, 3901 Beaubien Blvd, Detroit, Ml 48201, USA; ahuq@med.wayne.edu

\section{REFERENCES}

1 Harrison JE, Bolton PF. Annotation: tuberous sclerosis. J Child Psychol Psychiatry 1997;38:603-14.

2 Potter $\mathrm{CJ}$, Huang $\mathrm{H}, \mathrm{Xu}$ T. Drosophila Tscl functions with Tsc2 to antagonize insulin signalling in regulating cell growth, cell proliferation, and organ size. Cell 2001;105:357-68.

3 Tapon N, Ito N, Dickson BJ, Treisman JE, Hariharan IK. The Drosophila tuberous sclerosis complex gene homologs restrict cell growth and cell proliferation. Cell 2001;105:345-55.

4 Gao X, Zhang Y, Arrazola P, Hino O, Kobayashi T, Yeung RS, Ru B, Pan D. TSC tumour suppressor proteins antagonize amino-acid-TOR signalling. Nat Cell Biol 2002;4:699-704.

5 Dan HC, Sun M, Yang L, Feldman RI, Sui XM, Ou CC, Nellist M, Yeung RS, Halley DJ, Nicosia SV, Pledger WJ, Cheng JQ. Phosphatidylinositol 3-kinase/ Akt pathway regulates tuberous sclerosis tumor suppressor complex by phosphorylation of tuberin. J Biol Chem 2002:277:35364-70.

6 Pickles A, Bolton P, Macdonald H, Bailey A, Le Couteur A, Sim CH, Rutter M. Latent-class analysis of recurrence risks for complex phenotypes with selection and measurement error: a twin and family history study of autism. Am J Hum Genet 1995:57:717-26.

7 Folstein SE, Piven J. Etiology of autism: genetic influences. Pediatrics $1991 ; 87: 767-73$

8 Bailey A, Le Couteur A, Gottesman I, Bolton P, Simonoff E, Yuzda E, Rutter M. Autism as a strongly genetic disorder: evidence from a British twin study. Psychol Med 1995;25:63-77.

9 Risch N, Spiker D, Lotspeich L, Nouri N, Hinds D, Hallmayer J, Kalaydjieva L, McCague P, Dimiceli S, Pitts T, Nguyen L, Yang J, Harper C, Thorpe D, Vermeer S, Young H, Hebert J, Lin A, Ferguson J, Chiotti C, Wiese-Slater S, Rogers T, Salmon B, Nicholas P, Myers RM. A genomic screen of autism: evidence for a multilocus etiology. Am J Hum Genet 1999;65:493-507.

10 IMGSAC. A full genome screen for autism with evidence for linkage to a region on chromosome 7q. International Molecular Genetic Study of Autism Consortium. Hum Mol Genet 1998:7:571-8.

11 Philippe A, Martinez M, Guilloud-Bataille M, Gillberg C, Rastam M, Sponheim E, Coleman M, Zappella M, Aschaver H, Van Maldergem L, Penet C, Feingold J, Brice A, Leboyer M, van Malldergerme L. Genome-wide scan for autism susceptibility genes. Paris Autism Research International Sibpair Study. Hum Mol Genet 1999;8:805-12.

12 Ashley-Koch A, Wolpert CM, Menold MM, Zaeem L, Basu S, Donnelly SL, Ravan SA, Powell CM, Qumsiyeh MB, Aylsworth AS, Vance JM, Gilbert JR, Wright HH, Abramson RK, DeLong GR, Cuccaro ML, Pericak-Vance MA. Genetic studies of autistic disorder and chromosome 7. Genomics 1999;61:227-36.

13 Liu J, Nyholt DR, Magnussen P, Parano E, Pavone P, Geschwind D, Lord C, Iversen P, Hoh J, Ott J, Gilliam TC. A genomewide screen for autism susceptibility loci. Am J Hum Genet 2001;69:327-40.

14 Barrett S, Beck JC, Bernier R, Bisson E, Braun TA, Casavant TL, Childress D, Folstein SE, Garcia M, Gardiner MB, Gilman S, Haines JL, Hopkins K, Landa R, Meyer NH, Mullane JA, Nishimura DY, Palmer P, Piven J, Purdy J, Santangelo SL, Searby C, Sheffield V, Singleton J, Slager S. An autosomal genomic screen for autism. Collaborative linkage study of autism. Am J Med Genet 1999;88:609-15.

15 IMGSAC. A genomewide screen for autism: strong evidence for linkage to chromosomes 2q,7q, and 16p. Am J Hum Genet 2001;69:570-81.

16 Buxbaum JD, Silverman JM, Smith CJ, Kilifarski M, Reichert J, Hollander E, Lawlor BA, Fitzgerald M, Greenberg DA, Davis KL. Evidence for a susceptibility gene for autism on chromosome 2 and for genetic heterogeneity. Am J Hum Genet 2001;68:1514-20.

17 Shao Y, Raiford KL, Wolpert CM, Cope HA, Ravan SA, Ashley-Koch AA, Abramson RK, Wright HH, Delong RG, Gilbert JR, Cuccaro ML, Pericak-Vance MA. Phenotypic homogeneity provides increased support for linkage on chromosome 2 in autistic disorder. Am J Hum Genet 2002;70:1058-61.

18 Cheadle JP, Reeve MP, Sampson JR, Kwiatkowski DJ. Molecular genetic advances in tuberous sclerosis. Hum Genet 2000;107:97-114.

19 Payton JB, Steele MW, Wenger SL, Minshew NJ. The fragile X marker and autism in perspective. J Am Acad Child Adolesc Psychiatry 1989;28:417-21.

20 Piven J, Gayle J, Landa R, Wzorek M, Folstein S. The prevalence of fragile X in a sample of autistic individuals diagnosed using a standardized interview. J Am Acad Child Adolesc Psychiatry 1991;30:825-30.

21 Lowe TL, Tanaka K, Seashore MR, Young JG, Cohen DJ. Detection of phenylketonuria in autistic and psychotic children. JAMA 1980;243:126-8.

22 Smalley SL, Tanguay PE, Smith M, Gutierrez G. Autism and tuberous sclerosis. J Autism Dev Disord 1992;22:339-55.

23 Hagberg B. Rett's syndrome: prevalence and impact on progressive severe mental retardation in girls. Acta Paediatr Scand 1985;74:405-8.

24 Kozma SC, Thomas G. Regulation of cell size in growth, development and human disease: PI3K, PKB and S6K. Bioessays 2002;24:65-71.

25 Stocker H, Hafen E. Genetic control of cell size. Curr Opin Genet Dev 2000;10:529-35.

26 Majerus PW. Inositols do it all. Genes Dev 1996;10:1051-53.

27 Kratz CP, Emerling BM, Bonifas J, Wang W, Green ED, Beau MM, Shannon KM. Genomic structure of the PIK3CG gene on chromosome band 
7q22 and evaluation as a candidate myeloid tumor suppressor. Blood 2002:99:372-4.

28 IMGSAC. Further characterization of the autism susceptibility locus AUTS1 on chromosome 7q. Hum Mol Genet 2001; 10:973-82.

29 York JD, Veile RA, Donis-Keller H, Majerus PW. Cloning, heterologous expression, and chromosomal localization of human inositol polyphosphate 1-phosphatase. Proc Natl Acad Sci U S A 1993;90:5833-7.

30 Geschwind DH, Sowinski J, Lord C, Iversen P, Shestack J, Jones P, Ducat L, Spence SJ. The autism genetic resource exchange: a resource for the study of autism and related neuropsychiatric conditions. Am J Hum Genet 2001;69:463-6

31 O'Connell JR, Weeks DE. PedCheck: a program for identification of genotype incompatibilities in linkage analysis. Am J Hum Genet 1998:63:259-66

32 Abecasis GR, Cherny SS, Cookson WO, Cardon LR. Merlin--rapid analysis of dense genetic maps using sparse gene flow trees. Nat Genet 2002;30:97-101

33 Sobel E, Lange K. Descent graphs in pedigree analysis: applications to haplotyping, location scores, and marker-sharing statistics. Am J Hum Genet 1996;58:1323-37.

34 Abecasis GR, Cookson WO. GOLD--graphical overview of linkage disequilibrium. Bioinformatics 2000;16:182-3.

35 Spielman RS, Ewens WJ. The TDT and other family-based tests for linkage disequilibrium and association. Am J Hum Genet 1996;59:983-9.

36 Schaid DJ. Case-parents design for gene-environment interaction. Genet Epidemiol 1999;16:261-73.

37 Kruglyak L, Lander ES. Complete multipoint sib-pair analysis of qualitative and quantitative traits. Am J Hum Genet 1995;57:439-54.
38 Kruglyak L, Daly MJ, Reeve-Daly MP, Lander ES. Parametric and nonparametric linkage analysis: a unified multipoint approach. Am J Hum Genet 1996;58:1347-63.

39 Martin ER, Kaplan NL, Weir BS. Tests for linkage and association in nuclear families. Am J Hum Genet 1997;61:439-48.

40 Martin ER, Bass MP, Kaplan NL. Correcting for a potential bias in the pedigree disequilibrium test. Am J Hum Genet $2001 ; 68: 1065-7$.

41 Martin ER, Monks SA, Warren LL, Kaplan NL. A test for linkage and association in general pedigrees: the pedigree disequilibrium test. Am J Hum Genet 2000;67:146-54

42 Domin J, Waterfield MD. Using structure to define the function of phosphoinositide 3-kinase family members. FEBS Lett 1997;410:91-5.

43 Chen WM, Deng HW. A general and accurate approach for computing the statistical power of the transmission disequilibrium test for complex disease genes. Genet Epidemiol 2001;21:53-67.

44 Knapp M. A note on power approximations for the transmission/ disequilibrium test. Am J Hum Genet 1999;64:1177-85.

45 Berridge MJ. Cell signalling. A tale of two messengers. Nature 1993;365:388-9.

46 Berridge MJ. Inositol trisphosphate and calcium signalling. Nature 1993;361:315-25

47 Czech MP. PIP2 and PIP3: complex roles at the cell surface. Cell 2000; 100:603-6.

48 Delmas P, Wanaverbecq N, Abogadie FC, Mistry M, Brown DA. Signalling microdomains define the specificity of receptor-mediated InsP(3) pathways in neurons. Neuron 2002;34:209-20.

49 Goffin A, Hoefsloot LH, Bosgoed E, Swillen A, Fryns JP. PTEN mutation in a family with Cowden syndrome and autism. Am J Med Genet 2001;105:521-4. 